\title{
Suicide in Pandemia
}

Silvia Pelàez

Dr. Silvia Pelàez is the founder of the NGO Ultimo Recurso, the first suicide prevention institution in Uruguay. She is also the creator of the first suicide prevention helpline in her country. She and her team are specialists in engaging community members in suicide prevention. She trains leaders to identify suicidal situations in the community and create rescue networks with health professionals, religious leaders, teachers, police officers and others.

Abstract. The aim of the lecture is to notice that Covid-19 is not the first pandemia in our history. To see the century XXI advantages will help us to accept our pain. We also remind public some tips to help. We also would like express a philosophical point of view about pandemia, suicide and life and death. 